
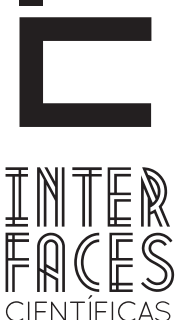

HUMANASE SOCIAIS

\title{
DA NARRATIVA DA AVENTURA À AVENTURA DA NARRATIVA - ETNOGRAFICIDADE: ALGUMAS VICISSITUDES
}

\author{
Jesana Batista Pereira ${ }^{1}$
}

\section{RESUMO}

0 presente artigo é uma revisão bibliográfica que tem como foco evidenciar algumas discussões sobre a mudança do método na etnografia. Se o típico método de representação do social era a constante contrastiva participar versus observar, há uma mudança do eixo da descrição para o da narração. 0 ponto de vista que interessa aqui é mostrar a importância da ênfase na narração para o entendimento da nova relação que se estabelece entre ficção e realidade. Relação esta que é preconizada pelo movimento Impressionista, o qual marca justamente a mudança de ênfase da descrição externa de um objeto imobilizado para o recurso da narração com a participação interpretativa e viva do real pelo autor. 0 que se coloca em dúvida é o pressuposto básico da arte mimética. As novas discussões teóricas se definem no contexto intelectual das culturas de que fazem parte os antropólogos e se expressam nos debates sobre modernidade e pós-modernidade. As dúvidas são postas sobre a representação em si e não apenas sobre como representar ex-povos coloniais. A pós-modernidade da antropologia está comprometida com esta crítica que, ao tomar consciência dos recursos linguísticos usados para a construção etnográfica assinala para o caráter textual da imagem do outro. Reinstalando sua ação em um espaço multidisciplinar, a antropologia se abre aos conceitos e instrumentos da linguística, a análise do discurso, a história e as contribuições de filósofos e epistemólogos.

\section{PALAVRAS-CHAVE}

Etnografia. Discurso. Narrativa. Outro. 


\section{ABSTRACT}

This article is a review that focuses on highlighting some discussions about changing the method in Ethnography. If the typical method of social representation was the constant contrastive participate versus observe, there is a change from the description to the narration. The point of view that interests me here is to show the importance of emphasis on narration for the understanding of the new correlation between fiction and reality. This correlation which is advocated by the Impressionist movement, which marks precisely the change in the emphasis of the external stationary object description to the resource of the narration with the interpretative and real live participation by the author. What is in doubt is the basic assumption of mimetic art. The new theoretical discussions are defined in the intellectual context of cultures that the anthropologists are part and express themselves in debates about modernity and post-modernity. The doubts are put on the representation itself and not just about how to represent ex-colonial people. The post-modernity of anthropology is committed with this criticism that, after being aware of linguistic resources used for building ethnography, notes textual characteristic on theimage of the other. Re-establishing your action in a multidisciplinary space, the anthropology opens to the concepts and tools of linguistics, discourse analysis, history and contributions of philosophers and epistemologists.

\section{KEYWORDS}

Ethnography. Speech. Narrative. Another.

\section{RESUMEN}

Este artículo es una revisión que se centra en destacar algunas discusiones sobre cómo cambiar el método de la etnografía. Si el método típico de representación social era la constante contrastiva participar frente a observar, hay un cambio de la descripción de la narración. El punto de vista que aquí interesa es demostrar la importancia del énfasis en la narración para la comprensión de la nueva relación entre ficción y realidad. Esta relación que es defendida por el movimiento impresionista, que señala precisamente el cambio en el énfasis de la descripción del objeto estacionario externo al recurso de la narración con la participación interpretativa y reales en vivo por el autor. Lo que se duda, es la asunción básica de arte mimético. Las nuevas discusiones teóricas se definen en el contexto intelectual de culturas que son parte de antropólogos y se expresan en los debates sobre la modernidad y la posmodernidad. Las dudas se ponen en la representación de sí mismo y no sólo sobre cómo representar ex pueblos coloniales. La posmodernidad de la antropología se ha comprometido a esta crítica, para darse cuenta de los recursos lingüísticos utilizados para la construcción carácter textual notas etnográficas de imagen en el otro. Reinstalar su acción en un espacio multidisciplinar, Antropología se abre a los conceptos y herramientas de lingüística, análisis del discurso, historia y aportes de los filósofos y los nacimientos de 1632.

\section{PALABRAS CLAVE}

Etnografía. Discurso. Narrativa. Otro. 


\section{INTRODUÇÃO}

Susan Sontag (1987. p. 164) aponta para uma característica fundamental da maior parte da produção intelectual do pensamento moderno: "a busca do Eu em seu Outro". E chama esta postura de "hegelianismo aplicado". Seria uma sensibilidade calcada no sentimento de "desamparo" trazido pelas mudanças históricas aceleradas. Neste sentido, aquela sensibilidade se movimentaria sob dois impulsos, ao mesmo tempo contraditórios e relacionados: "a rendição ao exótico, ao estranho, ao outro; e a domesticação do exótico, principalmente através da ciência”. ${ }^{2}$ As figuras do exótico aparecem, segundo a autora, na Ásia, no Oriente Médio, entre povos primitivos, na América mítica, nas energias impessoais do êxtase sexual ou da droga, na científica "neutralidade do valor", etc. ${ }^{3}$

O confronto com o outro e a descoberta de si, foi primordialmente uma experiência básica compartilhada por poetas, romancistas, filósofos e antropólogos, "no exílio voluntário" e nas "viagens compulsivas". Para esses profissionais, o próprio sentido do ato de escrever se funda numa situação de deslocamento (narrativa da aventura). Essa experiência básica coloca a antropologia, por meio da etnografia, bem como outros gêneros narrativos, como os lugares de onde se pode ver o como se dá essa experiência e como ela forja a figura do "outro" ou como a relação com o diverso, com o alhures, é experienciada. Não esquecendo que

2 Roger Bastide, por exemplo, um tanto quanto apaixonado, expressa este estado de espírito em Imagens do Nordeste Místico em Branco e Preto (1945), onde se diz "dividido entre um grande fervor e o desejo de fazer uma pesquisa objetiva", e considera que "o sociólogo que quer compreender o Brasil deve transformar-se em poeta". (Apud Laplantine, 1988, p.177). Em nível semelhante está o relato autobiográfico de Lévi -Strauss, Tristes Trópicos (1955). Mais cético que Roger Bastide, ele faz a apologia de um espírito nostálgico que se entristece com o passado sendo destruído a olhos vistos. Toma o partido da razão como consolo e desencanto necessário ( Sontag, 1987).

3 Quem aponta também para esta característica fundamental é James Clifford (1998) ao caracterizar a etnografia, tal como veio a ser concebida no século $\mathrm{XX}$, como parte, tanto cultural como estético, do ideário modernista. Na experiência etnográfica encontra-se a mesma atitude cultural dos escritores e artistas modernistas, ou seja, a busca de uma experiência "autêntica". os gêneros, "como qualquer instituição, destacam as características constitutivas da sociedade a que pertencem", porque, justamente, se instalam enquanto fenômeno de cultura (Todorov,1981, p. 52).

O caráter de deslocamento que caracteriza a viagem carrega em seu bojo o bom "motivo do encontro", não só do encontro, mas, também, o "motivo do reconhecimento - não reconhecimento", da perda, da obtenção, da descoberta. Tudo depende da predisposição de quem se desloca e de como ele percebe o deslocamento. Quem, por exemplo, desenvolve este tema é Bakhtin (1988, p. 124) quando aponta para o fato de que "[...] o motivo do encontro é um dos mais universais não só na literatura, mas em outros campos da cultura, e também em diferentes esferas da vida e dos costumes da sociedade". Contudo, adverte a esse respeito que "[...] no campo científico e técnico, onde impera o pensamento puramente conceitual, não se encontram os motivos como tais, mas sim o conceito de contato, que é seu equivalente".

No entanto, é preciso saber "quem" se desloca contando a aventura do "encontro" ou do "contato". Assim, o personagem-narrador de gêneros narrativos como a etnografia e a literatura, por exemplo, é o "indivíduo". O indivíduo que a ideologia dominante da cultura ocidental transformou de realidade concreta em [...] centro e foco do universo social, contendo dentro de si a sociedade (Da MATTA, 1983, p. 92). Assim, esse sujeito se constitui não só em "herói de uma biografia", por ser um "sujeito no mundo" e inscrito no domínio da história, como também em "princípio ativo de uma visão", por ser uma "individualidade criadora" que inscreve, no discurso que profere, imagens e interpretações daquilo que vê (BAKHTIN, 1992, p. 207)

Mas, voltando ao tema da viagem, por um lado, a situação de deslocamento, representada numa vasta 
"literatura de viagem" 4 , ao escritor abriu-lhe novos horizontes levando-o a tomar consciência do fato de que sua cultura não é a única no mundo. No entanto, da experiência do encontro com o diverso, com o diferente, assiste-se à utilidade da oposição como afirmação e descoberta de sua própria identidade. Em sendo assim, o diverso era tão somente uma questão espacial. Num estudo sobre a multiplicidade dos aspectos do gênero do romance do ponto de vista histórico, Bakhtin (1992, p. 223) nos mostra o princípio cognitivo que orienta a forma de percepção do "outro" (diversidade aberta pela descoberta de novos mundos) efetuada no tipo de romance que ele denomina de "Romance de viagem". ${ }^{5}$ Assim, ele explicita que:

[...] o que caracteriza o tipo de romance de viagem é uma concepção puramente espacial e estática da diversidade do mundo. 0 mundo apresenta-se como uma justaposição espacial de diferenças e contrastes; a vida é formada de uma sucessão de situações diferenciadas e contrastantes: sucesso-insucesso, felicidade-infelicidade, vitória-derrota. (...) A ausência do tempo histórico faz que a ênfase recaia unicamente nas diferenças e nos contrastes. Os vínculos consubstanciais são quase inexistentes. Fatos sócio-culturais tais como etnia, país, cidade, grupo social, grupo profissional, não são percebidos no conjunto integrado que constituem. É isso que explica uma característica particular desse tipo de romance: o grupo social, a etnia, o país, os costumes são registrados num espírito 'exótico' ou, seja, as distinções e os contrastes, a alteridade, são objeto de uma percepção bruta. É isso que explica também o caráter naturalista dessa variante romanesca: o mundo se desagrega em coisas isoladas, fenômenos e acontecimentos, que são justapostos ou se sucedem (BAKTHIN, 1992, p. 223)

Por outro lado, a experiência do contato da Europa com o Novo Mundo, representada primordialmente nas cartas e relatórios dos navegadores e exploradores, elaborou uma conceituação do diverso de modo a justificar

4 Laplantine (1988) dá exemplos de algumas obras desta envergadura lembrando que no Ocidente os grandes livros de aprendizagem são relatos de viagem. Cito aqui alguns mais representativos: Bourlinguer (Cendrars); A Modificação (Michel Butor); A llha (Robert Merle); e ainda Robinson Crusoé; Moby Dick; A Volta ao Mundo em Oitenta Dias; etc. 5 As narrativas de viagem são uma moda que surge no Renascimento e permanece até o século XVIII com ampla aceitação do público. a diversidade. 0 "outro" era "homens de natureza" ou "povos de hábitos aberrantes". A Europa considerava que a humanidade diversa podia ter acesso à cultura. 0 princípio cognitivo que informa esta concepção alude ao fato de que "enquanto o primitivo - cosmologizando - divinizava o branco, este - antropologizando - afirmava a si mesmo, subumanizando o primitivo" (MAZZOLENI, 1992).

É nesse métieraventureiro - mas primordialmente colonialista - que a antropologia se inicia, principalmente por meio da prática do trabalho de campo que, no caso, tratava mais de expedições exploratórias cujas preocupações eram estratégicas. Contudo foi somente em meados do século XIX que os trabalhos indiscutivelmente antropológicos foram escritos. 0 que os distinguia das demais obras científicas era o método comparativo. Ou, dito de outro modo:

[...] a gênese de uma conceituação do diverso não depende tanto da tomada de consciência experimentada por uma oposição entre o SI MESMO e O DIVERSO DE SI MESMO, mas do DIVERSO colhido deliberadamente como oposição e da consequente relação de subordinação do objeto (o diverso) ao sujeito (o si mesmo pensante) (MAZZOLENI, 1992, p 70).

Por isso é que não é por demais lembrar que o exotismo e a alteridade não são invenções da antropologia. 0 que ocorre é uma situação oposta. "Ela é que foi inventada para domesticá-los, torná-los culturalmente digeríveis ao paladar cultural do Ocidente" (RAMOS, 1994, p. 67). A convicção da existência de uma outridade enquanto modelo alternativo, contudo, não muda a orientação cultural da Europa que entra em contato com o Novo Mundo, na medida em que, ao entrarem em palco as análises das formas de produção e das estruturas de poder, o "Novo Mundo" torna-se "Terceiro Mundo", e o "outro" uma alternativa; mas, uma alternativa em termos ocidentais. 0 "outro" existe, mas é "interno" ao Ocidente.

Nesta nova ordem de coisas, a sedimentação de uma "discursividade" própria delimita o campo epistemológico da antropologia tida então como discipli- 
na científica. A exposição objetiva dos fatos legitima essa "discursividade" que, pretendendo "explicar", cria todo um mundo de representações no qual desfila toda uma outridade que se sabe apenas o diferente. 0 antropólogo-cientista torna-se o profissional em trabalho de campo e seus enunciados são legitimados pelo que James Clifford (1998) denomina "autoridade etnográfica", ou seja, uma autoria baseada no "você está lá, porque eu estive lá".

0 trabalho de campo torna-se a chave da originalidade e do valor científico da disciplina, sendo Argonautas do Pacífico Ocidental de Malinowski (1922) considerado o texto-fundador do método da observação participante, que legitima esse modo de conhecimento de "outras culturas". 0 processo de construção do conhecimento antropológico encontra no "realismo-etnográfico" um novo gênero literário que, dotado de uma série de "convenções textuais", cria o "efeito de realidade holística".

Neste tipo de texto, a fragmentada e "dialógica" experiência de campo vira "um monólogo encenado pelo etnógrafo, voz única que subsume todas as outras e sua diversidade à sua própria elaboração" (MAZZOLENI, 1992, p. 142). Neste âmbito, o prodigioso feito da produção desses textos foi o de "realizar a função oposta de qualificar na diversidade e de quantificar as diversidades" (MAZZOLENI, 1992, p.157). Um relativismo que instala o diverso num eixo de julgamento valorativo, no qual se surpreende a relativa superioridade da civilização europeia.

Outra expressão contundente da corrente realista - cujo pressuposto básico está na preocupação com relações de causa e efeito, nas quais importam menos os acontecimentos, os fenômenos que ocorrem no plano da realidade histórica, que as causas e circunstâncias que lhes deram origem - é o Romance Realista. Nele se situam a imagem de um homem em formação, que prescreve suas emoções, suas descobertas a uma finalidade objetiva.
“É o desenrolar do destino e da vida do herói preestabelecido que confere conteúdo ao enredo. O próprio caráter do homem, suas modificações e sua evolução não se transformam em enredo romanesco". É que os acontecimentos e episódios nele representados - embora consistam em movimentar o herói no espaço, na hierarquia social, ora se aproximando, ora se afastando de seu objetivo, modificando-lhe o destino, a situação na vida e na sociedade - não the irrompem nenhuma alteração, ele permanece sempre igual a si mesmo (BAKHTIN, 1992, p. 203)6. De forma resumida, o seu desenvolvimento se confunde com um mundo que muda, mas que só muda "graças ao processo de investigação de quem o estuda" (BAKHTIN, 1992, p. 204). Pois bem, grosso modo, isto persuade a inferir que o ethos que fundamenta estes dois fenômenos culturais, a etnografia e o Romance, é o mesmo, na medida em que tanto o encontro quanto o contato não significam uma interrupção da orientação ocidental que, antropologizando, reduz o cosmo à medida do homem.

Ao tentar dar expressividade ao então movimento rápido e profuso da sociedade e da cultura, a moderna narrativa romanesca vem romper com o princípio da objetividade encontrado na estética clássica que vai até finais do século XIX. Se nesta o "foco narrativo" se compunha na figura do narrador que adotava uma perspectiva realista, na qual a narrativa contava-se a si mesma, na moderna esta objetividade se esvai e o narrador é substituído por uma voz diretamente envolvida no que narra. Isto porque o mundo já não é um dado objetivo, mas vivência subjetiva.

6 Machado de Assis, por exemplo, trabalha com essa concepção no seu texto, quando, usando o procedimento da ironia, mostra que a defasagem entre convicções e ação não provoca nenhum tipo de tensão nos indivíduos. Vejam-se Memórias Póstumas de Brás Cubas.

7 Segundo nos informa Carvalho (1981, p. 1), "a noção de 'ponto de vista' ou 'foco narrativo' teve sua origem, ou a sua consagração nos prefácios de Henry James para a reedição de seus romances, nos quais não havia nenhuma preocupação de exposição sistemática". No método por ele preconizado, "o autor tem uma função bem específica, e extremamente discreta: 'não o que ele observa, mas o observador observando é o assunto, e a mente deste o nosso teatro'". 
Guardando as idiossincrasias autorais responsáveis por vários estilos desta forma narrativa, pode-se afirmar que, de modo geral, na narrativa moderna, a intenção artística do uso do fluxo da consciência ${ }^{8}$ é a de:

[...] fazer com que se confunda ou até, que desapareça totalmente, a impressão de uma realidade objetiva, dominada perfeitamente pelo escritor. Aqui o escritor atinge a impressão mencionada colocando-se a si próprio, por vezes, como quem duvida, interroga e procura, como se a verdade acerca da sua personagem não lhe fosse mais bem conhecida do que às próprias personagens ou ao leitor. Tudo é, portanto, uma questão da posição do escritor diante da realidade do mundo que representa; posição que é, precisamente, totalmente diferente da posição daqueles autores que interpretam as ações, as situações e os caracteres das suas personagens com segurança objetiva, da forma que, anteriormente, ocorria em geral (AUERBACH, 1987, p. 482).

Do ponto de vista cognitivo, o que marca a reviravolta na narrativa moderna é o método. 0 típico método de representação do social torna-se a constante contrastiva "participar" versus "observar". Há uma mudança do eixo da descrição para o da narração ${ }^{9}$. Assim,

[...] à medida que o autor assume a posição de câmera de cinema, envolvendo-se com o plano objetal que descreve, estabelece um tipo de poíesis ou criação literária numa práxis produtiva, que integra sujeito e objeto. Neste caso, não há elemento passivo, não há objeto de descrição; só há narração dramática e participativa (LOBO, 1984, p. 146).

8 O termo "fluxo da consciência" foi criado pelo psicólogo William James e apropriado pela crítica literária. Em literatura "trata-se da especialização de um determinado modo de foco narrativo". [...] a ficção do tipo fluxo de consciência [...] procura apresentar, através de uma linguagem truncada ou desordenada, o pensamento ainda não claramente formulado do ponto de vista lógico ou lingüístico (Carvalho, 1981, p.61).

9 Uma distinção entre "descrição" e "narração" é dada por Gérard Genette (1976) quando diz que "toda narrativa comporta, com efeito, embora intimamente misturadas e em proporções muito variáveis, de um lado representações de ações e de acontecimentos, que constituem a narração propriamente dita, e de outro lado representações de objetos e personagens, que são o fato daquilo que se denomina hoje de descrição". Como ele mesmo observa, não há um imobilismo antagônico e rígido dessas duas posições, o que caracteriza exatamente a literatura moderna.
Deste quadro podem-se retirar inúmeras questões relativas ao romance contemporâneo. 0 ponto de vista que me interessa aqui é o da importância da ênfase na narração para o entendimento da nova relação que se estabelece entre ficção e realidade. Relação esta que é preconizada pelo movimento Impressionista, o qual marca justamente a mudança de ênfase da descrição externa de um objeto imobilizado para o recurso da narração, com a participação interpretativa e viva do real pelo autor.

0 que acontece é que o modelo realista que se pautava no distanciamento do narrador da narrativa, na verdade, não satisfez a certos autores. 0 que se colocava em dúvida era o pressuposto básico da arte mimética: "[...] o de que existe uma realidade anterior sobre a qual a obra de arte deve ser modelada" (STAM, 1981, p. 55). A busca do caráter narrativo coloca a linguagem como realidade fundante. Deste modo, "[...] a junção da ficção e realidade torna-se o objetivo de escritores que gradativamente tiraram da literatura a função de representar a realidade" (MARTINS, 1988, p. 11). Isto alude ao fato de que pensar a linguagem, não só no seu sentido artístico, mas também linguístico, antropológico, filosófico e cultural, significa que a linguagem é constitutiva e não acidental.

0 que acontecia à obra Realista era um distanciamento do aspecto artístico em prol do científico, com um visível descompromisso com a obra. Assim é que alguns escritores "[...] subvertem a estrutura da voz narrativa realista, imprimindo-lhe um caráter objetivo antes ausente. Objetividade essa que se mistura com o aspecto subjetivo, para imprimir a relação criteriosa entre sujeito e objeto" (MARTINS, 1988, p. 11). Geralmente perfilam nas listas de escritores que realizam esta subversão, autores como Joyce, Virgínia Woolf, Thomas Mann, William Faulkner, Marcel Proust, Clarice Lispector, André Gide etc. 


\section{DA AVENTURA NA NARRATIVA}

O desenvolvimento contemporâneo das sociedades tradicionalmente estudadas pelos antropólogos as aproximou das metrópoles. Mudaram de status, os antropólogos não são mais "tradutores", e os "grupos subalternos já não se deixam representar tão impunemente por terceiros". Em cena hoje estão tanto os "africanistas" quanto os "africanos"; os "americanistas" quanto os "índios americanos" etc. (CANCLINI, 1993, p. 48). Se a mitologia heroica continua, a aventura por mares nunca dantes navegados agora se direciona para o discurso, nunca dantes questionado. As novas discussões teóricas se definem no contexto intelectual das culturas de que fazem parte os antropólogos e se expressam nos debates sobre modernidade e pós-modernidade. As dúvidas são postas sobre a representação em si e não apenas sobre como representar ex-povos coloniais.

Assim, "o barulho dos pós-modernos"10 é justamente o questionar, "a partir da própria teoria do conhecimento científico, as condições em que se produz o saber antropológico", e o "expor o modo pelo qual este saber é transmitido através de textos e instituições onde seu sentido é construído" (TRAJANO FILHO, 1988, p. 122).

Neste sentido, a pós-modernidade da antropologia está comprometida com esta crítica que, ao tomar consciência dos recursos linguísticos usados para a construção etnográfica, assinala para o caráter

10 Que Barulho é Esse, o Dos Pós-Modernos? Este é o título de uma crítica que Wilson Trajano Filho fez ao livro Writing Culture: The Poetics and Politics of Ethnography. Trata-se de uma coletânea de ensaios organizada por James Clifford e George E. Marcus, publicado em Berkeley: University of California Press, 1986. Como diz Trajano Filho, a "federação interpretativa americana" está neste livro representada. O teor desta vertente antropológica afirma-se na oposição a outras vertentes da disciplina, tais como a materialista, a estruturalista etc., "e através de oposições internas que a organizam". Ressaltando o espírito contundente e sagaz dessa crítica, apenas quero reter nesta nota um caráter geral de sua impressão: "Writing Culture saudavelmente advoga uma concepção abrangente para a etnografia, uma dimensão ética para o fazer antropológico e uma ênfase nas instâncias específicas do discurso, em vez do foco na representação do mundo" (TRAJANO FILHO, 1988, p.135). textual da imagem do outro. Reinstalando sua ação em um espaço multidisciplinar, a antropologia se abre aos conceitos e instrumentos da linguística, à análise do discurso, à história e às contribuições de filósofos e epistemólogos. Os autores pós-modernos se valem, portanto, de autores como Foucault (noções de autor e episteme); Wittegenstein, Gadamer e Ricoeur (procediementos hermenêuticos); Austin e Searle (jogos de linguagem) (CANCLINI, 1993).

Esta vertente incide suas críticas às antropologias "tradicionais"11, focalizando a propriedade de seus discursos, os quais repousam na ideia de que a estrutura do mundo é externa à obra etnográfica. Por outro lado, defende "[...] uma postura humanística para o fazer antropológico e o caráter provisório e parcial de toda análise cultural” (TRAJANO FILHO, 1988, p. 137).

Em sendo a etnografia escrita, a sua textualidade the garante um caráter preponderantemente literário e fracamente científico. Clifford Geertz (1978), por exemplo, no que diz respeito a uma reflexão do interior da disciplina encara, neste sentido, o texto antropológico produzido pelo antropólogo como ficção. Geertz elucida que tanto o texto etnográfico e o literário se baseiam numa "fictio" ou, seja, numa "fabricação", mas ambos se diferenciam quanto às condições de sua criação e o seu enfoque. Mariza Peirano (1992, p. 136) resgata esta visão de Geertz quando diz que nela a ênfase recai “[...] no aspecto artesanal da construção etnográfica, abrindo-se espaço para criações e construções literárias que independem de definições do que seja arte, literatura, ciência ou história".

Neste âmbito, a alteridade com a qual se depara o etnógrafo é a sua própria atividade de reflexão escrita. Quando fala da relação entre a crítica de ficção e a crítica da escritura etnográfica, Geertz (1989, p. 153) aponta para o fato de que:

11 Estas antropologias tradicionais são aquelas que se fundam no paradigma "racionalista", ou "estrutural-funcionalista", ou ainda no "culturalista" (CARDOSO DE OLIVEIRA, 1988). 
[...] os Antropólogos estão possuídos pela idéia de que os problemas metodológicos centrais implícitos na descrição etnográfica têm que ver com a mecânica do conhecimento: a legitimidade da intuição, da empatia e demais formas similares de cognição; a verificabilidade dos informes internos sobre os sentimentos e pensamentos de outros povos, o estatuto ontológico da cultura.

0 que ele assinala então é que o conhecimento se gesta no texto e não nos problemas metodológicos implícitos na descrição etnográfica.

Sobre esse debate, Marylin Strathern (1987) aponta para o fato de que o êxito de determinadas narrativas está mais no confronto de estratégias textuais do que no confronto de problemas. Neste sentido, as descrições se apresentam para ela como "ficções persuasivas", na medida em que a questão não está simplesmente em como dar vida a certas cenas, mas como dar vida a ideias.

Assim, fundamentalmente, as novas propostas giram,

[...] em torno da ligação entre pesquisa de campo e construção de etnografias. Estão intimamente relacionados na construção etnográfica, a pesquisa de campo (incluindo, naturalmente, a escolha do objeto), a construção do texto e o papel desempenhado pelo leitor (PEIRANO, 1992, p. 87).

É neste sentido que a antropologia contemporânea se vê envolvida num amplo debate cultural, e uma de suas concepções mais caras, a de Representação, é posta em dúvida. Alternativas são propostas ao modo de conhecimento operado por esta categoria. S. Tyler, um dos críticos pós-modernos, propõe o "evocar" como alternativa à Representação e diz que aquela categoria libertaria a etnografia da mímesis:

[...] a característica do 'evocar', mais que 'representar', é que liberta a etnografia da mímesis, e de um pouco apropriado modo de retórica científica que alinhava 'objetos', 'fatos', 'descrições', 'induções', 'generalizações', 'verificações', 'verdade' e conceitos sem paralelo, seja na experiência do trabalho de campo etnográfico ou na escrita na etnografia (TYLER apud AZZAN JÚNIOR, 1993).
Muitos incidentes vêm a tornar claro que os textos antropológicos não podem ser lidos como uma "taquigrafia" de experiência descrita. Dentre eles a publicação dos Diários de Malinowski, as críticas de Rebeca B. de Holmes ao livro de Florinda Donner, Shabono (1983), as refutações de Dereck Freeman à interpretação de Margaret Mead sobre os samoanos, os ataques à obra de E. Leach sobre a Birmânia (Canclini, 1993). Desta forma o conceito de cultura ganha nova atualidade, uma vez que ela deixa de ser concebida como um objeto a descrever, como um corpus estável de símbolos e significados a interpretar. Assim, as alternativas pós-modernas têm reivindicado, à etnografia, novos princípios discursivos, mesmo porque o antropólogo não é mais:

\begin{abstract}
"um sujeito cognoscente privilegiado". Nesse contexto alternativo, "assim que o dialogismo e a polifonia são reconhecidos como modos de produção textual, a autoridade monofônica é questionada, aparecendo como uma característica de uma ciência que pretendeu representar culturas" (CALDEIRA, 1988, p. 142).
\end{abstract}

Portanto a Antropologia, inventada para domesticar o exótico e a alteridade de forma a "torná-los culturalmente digeríveis ao paladar cultural do Ocidente" (RAMOS, 1994, p. 68), figura aqui como um campo discursivo dentro do qual os seus diversos esforços analíticos traduzem, hoje mais do que nunca, a aventura de uma escritura, sempre em busca da constituição de novas formas de conhecimento. Afora as classificações de seus momentos discursivos como tradicional, moderno ou pós-moderno, o que fica como referente é a vocação primordial de sua prática, ou seja, a de gerar conhecimento.

Contudo, não se deve esquecer que, para essa disciplina, pessoas representam tradições, pensamentos, teorias. Em antropologia, determinados indivíduos "estabelecem os termos discursivos em cujo marco outros posteriormente se movem [...]". Remetem não só a obras concretas e particulares "[...] como a todo um estilo antropológico de ver as coisas" (Geertz, 1989, p. 29). É o estabelecimento do que Paul 
Rabinow chama de "comunidades interpretativas", ou o que Pierre Bourdieu sustenta sobre as implicações do sistema de relações entre agentes e as instituições que intervêm na produção, circulação e apropriação do saber (Apud CANCLINI, 1993).

As condições de leitura hoje são diversas. E, nestas condições, a etnografia, como gênero narrativo se instala, no processo de produção cultural - mas também em condições transculturais - como "[...] uma interpretação entre outras possíveis. A relativização é relativizada, pois em conta agora se leva o leitor" (MONTEIRO,1993, p. 120). Neste sentido, mostrar-se atento à realidade do texto é um dos desafios colocados, hoje, para a antropologia. Assumir-se como acontecimento de ficção, mesmo porque nem toda ficção é literária, não é ser vítima de uma ilusão de realidade, ou mesmo perder, supostamente, sua força ao abrir mão de sua vontade de explicar alguma coisa, mas é mostrar-se atento à realidade do texto ${ }^{12}$. No terreno da ficcionalidade se inscreve a aventura da discursividade. Tomar esta aventura como possibilidade de constituição de novas formas de conhecimento é o desafio colocado, hoje, para a antropologia.

Ainda com relação à propositura deste ensaio, é mister mencionar algumas produções etnográficas que efetivamente incorporaram as novas regras ou alternativas textuais propostas pelo pós-modernismo ${ }^{13}$ em antropologia. São experimentos narrativos que se aproximam do que estamos chamando de "aventura da narrativa”, uma vez que seus "autores/antropólogos" enfrentam, com estilos diferentes, a escritura narrativa com o afã de desvelar as escrituras culturais

12 A este respeito Geertz (1989) diz que [...] do mesmo modo que a crítica de ficção e poesia se alimenta muito mais de um compromisso efetivo com a ficção e poesia mesmas, que de noções importadas sobre o que ambas deveriam ser, a crítica da escritura etnográfica (que em rigor não tem nada de nenhuma delas, mas em um sentido amplo é tão poética como ficcional) deveria nutrir-se de idêntico compromisso com a escritura mesma e não de preocupações sobre o que deve parecer para que se a qualifique de ciência".

13 O pastiche dos comentários; o jogo de imagens; o achatamento da história; a descontextualização; a neutralidade e a textualidade são algumas características do pós-modernismo apontadas por Fredric Jameson (Apud Caldeira, 1988, p. 150) de modo a thes permitir significar da mesma maneira selvagem e subversiva que caracteriza a natureza da linguagem.

Richard Price em First-Time (1983), se dedica a estudar, por meio da memória oral, o conhecimento que têm os Saramakas, descendentes de escravos que vivem no Suriname, sobre um evento que ocorreu há mais de dois séculos e que compreende a sua fuga em massa das plantations. Price adota uma "perspectiva local" e transforma o "antropólogo/autor em apenas um entre vários produtores de interpretações".

Outro experimento narrativo é Waiting (1985) de Vincent Crapanzano. Nessa obra ele estuda os bran$\cos$ da África do Sul, um grupo dominante. Em termos de estilo, Crapanzano adota a plurivocalidade, uma vez que intenta transformar seus informantes em co-autores por meio da reprodução de suas vozes. Michael Taussig também redefine a posição do antropólogo como autor do texto em seu Shamanism,

Colonialism and the Wild Man (1987). Nessa obra, diferentemente das duas anteriores, Taussig se mostra interessado em fazer uma crítica cultural e uma crítica da sua sociedade. Usa a montagem como técnica textual básica, uma vez que "nega a possibilidade de dizer o que os outros são". A montagem torna isto viável na medida em que as possíveis associações e ligações entre os planos não são expressas. Não se coloca como tarefa revelar uma ordem, mas pela fragmentação, sugerir possíveis.

Todas essas informações sobre tais obras são fornecidas por Teresa Pires Caldeira (1988) que, depois de desenvolver algumas importantes questões sobre a autoria e a pós-modernidade em Antropologia, provoca o debate ao marcar sua posição em defesa da necessidade de se definir, além de tipos de representação possível sobre os outros e procedimentos de construção, que tipo de crítica e política se quer fazer.

Mas, continuando a "aventura da narrativa", os supostos ou vicissitudes enfrentadas pelas produções 
etnográficas de tradição escrita no que diz respeito ao papel da linguagem dos textos na descrição e criação da realidade histórica, encontram, também, ressonâncias ao considerar a introdução dos modernos instrumentos de registro audiovisuais ao aparelho de investigação do antropólogo. A linguagem visual, seja ela "fixa" (fotografia) ou "animada" (vídeo e cinema), também fabrica "textos”. E uma das questões colocadas neste âmbito de discussão se situa no como utilizar das linguagens desses recursos audiovisuais para observar e investigar, descrever e compreender visualmente os fatos humanos.

No Primeiro Seminário de Antropologia Visual ${ }^{14}$ realizado no quadro do 11 Festival Latinoamericano de Cinema dos Povos Indígenas, sediado na cidade do Rio de Janeiro, de 06 a 08 de Setembro de 1987, foram propostos três temas gerais para serem desenvolvidos pelos grupos de trabalho e apresentados relatórios. Os temas versavam sobre o seguinte: “Do bloco de notas à Câmara", "Metodologia e meios de aplicação do visual" e "O vídeo como instrumento de afirmação étnica”. Fora pela primeira vez no Brasil que se apresentava uma reflexão sobre o status da Antropologia Visual enquanto ciência. Etienne Samain participou como Coordenador e Relator do Grupo Fotografia, com a participação de Hélio Sôlha e Regina Raick, e Március Soares Freire como Coordenador e Relator do Grupo Vídeo-Cinema, com a participação de Regina Calazans e Sônia M. Brandão.

No que tange às questões relatadas pelo Grupo Fotografia em Antropologia Visual, ficou clara a defesa da necessidade de se reconhecer o visual como fonte primordial de informação e de produção de conhecimento, a despeito de a formação acadêmica ser predominantemente verbal. Foi lembrada pelo grupo a experiência realizada por Gregory Bateson e Margaret Mead, que já no início da década de 40 utilizavam o aparato e a linguagem fotográfica como subsídios relevantes para uma aproximação visual da cultura.

14 Primeiro Seminário de Antropologia Visual. Relatórios dos Grupos de Trabalho. 1987, mimeo.
Ressaltaram a necessidade de uma "alfabetização" às linguagens visuais, não no sentido de se formar nas escolas de Antropologia "artistas" da imagem, mas pessoas habilitadas a se utilizar das linguagens desses recursos não só como suporte ilustrativo, mas como instrumento da pesquisa, uma vez que o conhecimento da estética própria a cada meio visual pode tornar mais eficiente a transmissão da informação. Além do que, apontaram, também, para a necessidade de se criar um instrumental teórico de decodificação do produto visual.

As discussões acerca do vídeo como instrumento de afirmação étnica giraram em torno da questão de uma “Antropologia da Devolução". Frisou-se que a devolução poderá servir a uma re-apropriação crítica das imagens pelas pessoas que nelas se encontram no sentido de representar a possibilidade de passar aos outros aquilo que se descobriu deles mesmos e de nós.

Quanto ao cinema, o Relatório do Grupo de Trabalho "Cinema e Vídeo", abordou as várias implicações subjacentes à apropriação da linguagem desses meios pela Antropologia que, tradicionalmente, tem se apoiado na linguagem escrita. Uma primeira observação feita diz respeito ao estigma que o cinema carrega de operar com uma organização espaço-temporal passível de manipulações ideológicas, e neste sentido afastar-se de uma apreensão objetiva da realidade, suposto de uma dada concepção de ciência que suporta mal esta possibilidade. Em relação a esta questão, enfatizaram a impossibilidade desta pretendida objetividade em termos absolutos, uma vez que no recorte espaço-temporal efetuado pelo "observador-cineasta”, já há a criação de outra realidade.

Nesse âmbito da questão detectam um dilema que deve ser enfrentado com o desenvolvimento de uma sistemática nos procedimentos de pesquisas onde os meios audiovisuais fazem parte do instrumental envolvido, qual seja, o fato de que, na maioria das vezes, as pessoas, ou são antropólogos sem conhecimento suficiente da especificidade de suas linguagens, ou 
são cineastas sem iniciação antropológica. Neste caso, as discussões caminharam em direção à especificidade do filme antropológico em oposição ao filme documentário-jornalístico. Segundo o relatório, o antropólogo tem melhores condições de realizar um filme-pesquisa em virtude de sua formação, uma vez que ele pode decodificar a cultura estudada melhor que outro especialista. Estabeleceu-se que a diferença fundamental entre o filme jornalístico e o filme antropológico reside na maneira de abordar o assunto.
A interação cineasta/antropólogo foi a tônica desse Relatório, levantando-se então a questão de se saber até que ponto a falta de preparação técnica do antropólogo não comprometeria a apreensão do real e se seria possível ao técnico compreender de maneira satisfatória o sentido da cultura observada, a tal ponto que the fosse possibilitada a realização de um filme antropológico.

\section{OS IMPONDERÁVEIS DA ESCRITURA CINEMATOGRÁFICA}

A discussão sobre o uso da imagem na antropologia, como pontuado até aqui, tem como referência principal a etnografia e a descrição de culturas, de sociedades e de relações sociais. A questão do diálogo entre o rigor científico e, especificamente, a arte cinematográfica tem, no entanto, acompanhado esta discussão, mesmo porque traçar paralelos ou cruzamentos entre cinema e antropologia enquanto dois campos discursivos é um empreendimento complexo, pois ambos desenvolveram-se simultaneamente no final do século XIX e sempre tiveram em comum um mesmo movimento: a descoberta da alteridade.

Se, por esta época, a antropologia passava à prática do trabalho de campo, o cinema se incorporava às expedições científicas, coloniais e às viagens de passeio. A busca do outro passa a ser o foco, também, do cinema etnográfico. A associação do cinema com a antropologia trouxeram novas revelações acerca do fazer etnográfico e da construção de narrativas, assim como também toda uma discussão em torno da natureza do filme documentário. Uma expressão sintomática da importância do entrecruzamento destas duas práticas foi a criação, em Dezembro de 1952, do Comitê do Filme Etnográfi-

co. A criação deste Comitê foi o resultado de uma reunião entre cineastas e antropólogos no Museu do Homem, de Paris, com o objetivo de partilharem suas experiências comuns. Este Comitê teve como um dos seus principais representantes o antropólogo-cineasta Jean Rouch ${ }^{15}$.

O conceito de filme etnográfico comparado ao filme documentário foi o tema do Seminário I da Primeira Mostra Internacional do Filme Etnográfico referido em nota abaixo. Teve como participantes Clarice Peixoto (antropóloga); Henri Gervaiseau (pesquisador da História do Cinema e produtor de imagens); Sílvio Da-Rin (realizador de filmes atuando como técnico, produtor e diretor) e Ana Maria Galano (coordenadora do Navedoc do IFCS).

0 teor dos debates girou em torno da necessidade de se pensar o objeto mesmo da antropologia visual, assim como as condições de utilização

15 In MONTE-MÓR, Patrícia e PARENTE, José Inácio (orgs.) Cinema e Antropologia: Horizontes e Caminhos da Antropologia Visual. Trata-se do resultado editado de uma série de quatro seminários realizados durante a Primeira Mostra Internacional do Filme Etnográfico, realizada no Rio de Janeiro em 1993. Reuniram-se especialistas da área do cinema e da antropologia discutindo questões relativas a conceitos, marcos históricos, linguagem, produção, parcerias, distribuição e acervos. 
dos instrumentos de registro de imagem e som. 0 que se observa é uma discussão centrada em um suposto dilema instaurado pelas diferentes concepções tanto de cinema quanto de antropologia que, a despeito das preocupações e experiências particulares dos participantes, condizentes com seus respectivos campos de atuação profissional, calcava as reflexões a partir de uma tensão entre certo empirismo presente nas preocupações com o descrever fenômenos de modo a reproduzir ou revelar situações, e a perceptível inevitabilidade do "espetáculo" (construção), uma vez que é evidente que o ponto de vista do observador constrói o objeto observado dentro de uma estética particular de narração, por meio da reconstituição das situações sociais.

Entra aí a questão da autoria e a presença do antropólogo/cineasta, também, como um personagem a enfrentar os imponderáveis da escritura cinematográfica. Nesta interlocução de diferentes pontos de vista, a gênese das diferenciações e classificações do registro em imagem movimento em gêneros que guardam fronteiras precisas enquanto modo de conhecimento particular perde sua autoridade heurística na medida em que a própria natureza de qualquer linguagem não se funda em uma mímesis, e sim em uma póiesis.

Assim, filme etnográfico, documentário, espetáculo, todos estes gêneros compartilham da fabricação. Qualquer filme utiliza uma série de procedimentos para compor a narrativa, ou seja, planos, contraplanos, montagem. E neste sentido, Sílvio Da -Rin, um dos participantes do debate, advoga a fa- vor de uma antropologia do audiovisual e não uma ciência que utiliza materiais visuais. 0 que importa é que qualquer filme é passível de abordagem por parte de um antropólogo. Qualquer material visual é um documento para o pesquisador em ciências sociais. A presença das linguagens visuais repercute no estatuto do saber antropológico, e o antropólogo "está condenado a avançar na sua narrativa etnográfica a partir do pensamento imagético" (ROCHA, 1995, p. 117).

A linguagem visual, quando associada à escritura do texto etnográfico, denuncia-o como construção, revelando a natureza do conhecimento. Se a especificidade do humano é o conhecimento e a moral, sua condição é inventada, é construída, pois ao simbolizar o homem fabrica, não reproduz uma ordem de mundo pré-existente à denominação. Mesmo porque o conhecimento não é um espelho das coisas ou do mundo externo, seja sob a forma de palavra, de ideia, de teoria, de imagem. A linguagem e o pensamento elaboram uma tradução/reconstrução. Por isso não se vê o mundo, mas fabrica-se mundos, como lembram Maturana e Varela ${ }^{16}$ ao elucidarem as bases biológicas do entendimento humano. Ora, se toda reflexão se dá na linguagem e esta é uma realidade fundante, então teria-se tantos mundos diferentes quanto diferentes estruturas narrativas ou discursivas? 0 que rege a fundação? As elipses, as metáforas, os verbos, a literalidade, o imaginário, o onírico, o delírio, a incerteza, os signos?

\footnotetext{
16 MATURANA, Humberto \& VARELA, Francisco. "Conhecendo o Conhecer". In: A Árvore do Conhecimento - As Bases Biológicas do Entendimento Humano. São Paulo: Psy II, 1995.
} 


\section{CONSIDERAÇÕES FINAIS}

Ficções existem, e o cinema, etnográfico ou não, enfrenta a questão da representação do real. E, como lembra André Parente (1994, p. 142)17 "não se trata mais de usar o cinema para produzir um puro registro do real ou um conhecimento puro, mas de fazer do conhecimento uma ética, uma política”. E neste ponto ele lembra Deleuze quando afirma que o que se opõe à ficção não é o real, mas a potência de fabulação do povo. Esta potência é uma criação e uma afirmação do real como novo. Então, outro enfrentamento se impõe o fato de as ficções se transformarem em modelo de verdade.

Há várias definições de antropologia como há várias definições de cinema, mas ambos são formas de conhecimento. E o cinema é uma grande forma de conhecimento, uma forma de produção de novos espaços e tempos. A linguagem cinematográfica tem um papel ativo na criação e descrição da realidade his-

17 PARENTE, André. "Seminário III - Antropologia e Cinema: Questões de linguagem". In MONTE-MÓR, Patrícia e PARENTE, José Inácio (orgs) Cinema e Antropologia: Horizontes e Caminhos da Antropologia Visual. Rio de Janeiro: Interior Produções, 1994. tórica e, no âmbito da Antropologia Contemporânea, a aceitação do simbolismo imaginário como fonte do conhecimento humano é seu desafio, enquanto pesquisa sobre imagens e com imagens.

Nesse sentido, não é de todo estranha a afirmação de Deleuze de que o cérebro é uma imagem entre outras: existem imagens, as coisas mesmas são imagens, porque as imagens não estão na cabeça, no cérebro. Ao contrário, é o cérebro que é uma imagem entre outras. As imagens não cessam de agir e de reagir entre si, de produzir e de consumir. Não há diferença alguma entre as imagens, as coisas e o movimento ${ }^{18}$. Considera que o domínio do cinema está construído na base da imagem-movimento. Os signos, no cinema, não são signos linguísticos, mesmo quando sonoros ou vocais. Por isso o cinema, para Deleuze, trazer uma "matéria movente" que exige uma nova compreensão das imagens e dos signos.

18 DELEUZE, Gilles. Conversações,1972-1990. Rio de Janeiro: Ed. 34, 1992. 


\section{REFERÊNCIAS}

AUERBACH, Erich. Mímesis: a Representação da Realidade na Literatura Ocidental. São Paulo: Perspectiva, 1987.

AZZAN JÚNIOR, Celso. Antropologia e Interpretação: Explicação e Compreensão nas Antropologias de Lévi-Strauss e Geertz. Campinas, SP: UNICAMP, 1993.

BAKHTIN, M. Questões de Literatura e de Estética. São Paulo: UNESP - HUCITEC, 1988.

BAKHTIN, M. Estética da Criação Verbal. São Paulo: Martins Fontes, 1992.

CALDEIRA, T.P. A Presença do autor e a pós-modernidade em Antropologia. Novos Estudos. CEBRAP, 21, 1988.

CANCLINI, Nestor G. Antropólogos sob a lupa, Ciência Hoje, v. 15, n. 90, maio, 1993.

CARDOSO DE OLIVEIRA, R. A categoria de (des)ordem e a pós-modernidade da antropologia. In Sobre o Pensamento Antropológico. Rio de Janeiro, Tempo Brasileiro, CNPQ,1988.

CARVALHO, Alfredo Leme Coelho de. Foco Narrativo e Fluxo de Consciência: Questões de Teoria Literária. São Paulo: Pioneira, 1981.

CLIFFORD, James. A Experiência Etnográfica: Antropologia e Literatura no século XX. Rio de Janeiro: UFRJ, 1998.

DELEUZE, Gilles. Conversações, 1972-1990. Rio de Janeiro: 34, 1992.

GEERTZ, Clifford. A Interpretação das Culturas. Rio de Janeiro: Zahar, 1978.
GEERTZ, Clifford. El Antropologo como Autor. Barcelona: Ediciones Paidos Ibérica; Buenos Aires: Editorial Paidós, 1989.

GENETTE, Gérard. Fronteiras da Narrativa. In: Análise Estrutural da Narrativa (vários autores). Rio de Janeiro: Vozes, 1976.

LAPLANTINE, François. Aprender Antropologia. São Paulo: Brasiliense, 1988.

LOBO, Luiza. A Ficção Impressionista e o Fluxo de Consciência. In: VASSALO, Lígia (org.). A Narrativa Ontem e Hoje. Rio de Janeiro: Tempo Brasileiro, Comunicação 5, 1984.

MARTINS, Maria Teresinha. O Ser do Narrador nos Romances de Clarice Lispector. Goiânia: Cerne, 1988.

MATTA, Roberto A. da. Carnavais, Malandros e Heróis. Rio de Janeiro: Zahar, 1983.

MATURANA, Humberto \& VARELA, Francisco. A Árvore do Conhecimento - As Bases Biológicas do Entendimento Humano. São Paulo: Psy II, 1995.

MAZZOLENI, Gilberto. O Planeta Cultural: para uma Antropologia Histórica. São Paulo: Universidade de São Paulo, Instituto Italiano di Cultura di San Paolo e Instituto Cultural Ítalo-Brasileiro, 1992.

MONTE-MÓR, Patrícia e PARENTE, José Inácio (orgs.) Cinema e Antropologia: Horizontes e Caminhos da Antropologia Visual. Rio de Janeiro: Interior Produções, 1994.

MONTEIRO, Paula. Para uma Antropologia das Instituições Globais: o Estudo da Cultura na Igreja Católica. Cadernos CERU. São Paulo: Série 2/4, 1993. 
PEIRANO, Mariza G.S. Uma antropologia no plural: três experiências contemporâneas. Brasília: Universidade de Brasília, 1992.

RAMOS, Alcida Rita. Os Caminhos do Exotismo e o Indigenismo Brasileiro. Fortaleza, Fundação Waldemar Alcântara. Coleção Documentos. Série Antropologia, n. 2, 1994.

ROCHA, Ana Luiza Carvalho da. Antropologia das formas sensíveis: entre o visível e o invisível, a floração de símbolos. In Horizontes Antropológicos - Antropologia Visual. Ano 1, n. 2, 1995.

SONTAG, Susan. Contra a Interpretação. Porto Alegre: L\&PM, 1987.
STAM, Robert. 0 Espetáculo Interrompido: Literatura e Cinema de Desmistificação. Rio de Janeiro: Paz e Terra, 1981.

STRATHERN, Marilyn. Out of Context-The Persuasive Fictions of Anthropology. Current Anthropology. Volume 28, number 3, June 1987.

TODOROV, T. Os Gêneros do Discurso. São Paulo: Edições 70 (Coleção Signos), 1981.

TRAJANO FILHO, Wilson. Que Barulho é esse, o Dos Pós-Modernos? Anuário Antropológico/86. Universidade de Brasília: Tempo Brasileiro, 1988. 